\title{
La política exterior norteamericana y América Latina
}

VIGENGIA NORTEAMIERICANA EN LAS RELACIONES INTERNACIONALES

Los países latinoamericanos están pendientes de lo que sucederá a raíz del triunfo del Partido Demócrata en las recientes elecciones llevadas a cabo en Estados Unidos. Es comprensible que así sea. Cualquier cambio que se produce en. la esfera politica de las grandes potencias del mundo actual lógicamente puede tener incidencia fundamental en el devenir político y económico del resto del mundo. Esto es aplicable, en principio, a todos los paises, cualquiera sea su grado de desarrollo económico o político. En efecto, el mundo actual está organizado de manera tal que ciertos países - las grandes potencias- ejercen liderazgo en las relaciones internacionales. Ese liderazgo -que se basa y se manifiesta en una mayor capacidad económica, en un mayor potencial bélico y en un mayor prestigio-implica la facultad de ejercer una influencia predominante, algunas veces clecisiva, en las relaciones internacionales.

Va de suyo que la influencia puede ser mayor en el caso de los países en desarrollo. iestos son más vulnerables a los vaivenes de la política y de la economia mundiales. Dada la menor autonomía relativa de esos países, su capacidad de decisión. económica y política está, en gran parte, supeditada a los criterios que se adoptan en los países hegemónicos. Los países latinoamericanos -en mayor o en menor grado, según los casos- forman parte de aquella categoría de países más vulnerables. Categoría que algunos autores suelen denominar "países de la periferia" (distinguiéndolos así de los países del "centro") o "dependientes".

En resumidas cuentas, desde un punto de vista económico, a América Latina le interesa saber, por ejemplo, si Estados Unidos invertirá, y en qué condiciones, en todos y cada uno de los países de la

- Funcionario del BLD/INTAL, donde desempeña las funciones de Director de la revista Inlegración Latinoamericana. Este trabajo fue preparado bajo la exclusiva responsabilidad del autor $y$ no compromete a la institución a la cual pertenece. 
región - la regulación y control de las empresas multinacionales puede incluirse en estel tema-; si comerciará con ellos de manera favorable - disminuyendo sus barreras arancelarias para que los productos latinoamericanos puedan ingresar con mayor facilidad en el mercado norteamericano; financiando las exportaciones latinoamericanas hacia Estados Unidos; o también, concediendo facilidades financieras para las compras latinoamericanas de productos norteamericanos-; si contribuirá efectivamente en los planes tendientes a estabilizar en un nivel adecuado los precios internacionales de las materias primas, y los consiguientes ingresos que los países exportadores derivan de ellos; o si, finalmente, procurará facilitar la transferencia de conocimientos tecnológicos a los países en desarrollo. En realidad, estos diversos temas están íntimamente ligados: las decisiones que se adopten al respecto tendrán, necesariamente, que revestir un carácter sistemático.

Además, dada la disparidad entre los indicadores de la economía norteamericana y los de las economías latinoamericanas, la magnitud de un cambio en las relaciones entre ambas partes siempre es sentida con mayor fuerza y peso en el lado latinoamericano. Por ejemplo, si Estados Unidos decide no hacer una inversión de dólares en un pais latinoamericano, la repercusión de tal decisión negativa es considerablemente mayor en este país que en aquél. Dicho de otra manera, lo que puede pasar casi desapercibido en EE. UU., resultará extremadamente notorio en un país latinoamericano. A esto se deben agregar las repercusiones implícitas de una decisión negativa. Dado el predica. mento que suelen tener las decisiones que adopta Estados Unidos, en razón de su situación prestigiosa, las connotaciones de las mis. mas pueden trascender el asunto de que se trata $y$ aplicarse también a otros temas.

Desde un punto de vista político y de la seguridad interesa saber cuál será la actitud de Estados Unidos ante los distintos y cambian. tes regímenes políticos e ideológicos que se suceden en los países latinoamericanos. Pues de esa actitud dependerán las decisiones referentes a la calificación de esos países como aptos para recibir una consideración preferencial en los distintos foros internacionales -como las Naciones Unidas y la OEA- en donde se debaten las posiciones políticas -y sus correlatos jurídicos- de los países latinoamericanos. Muchos países latinoamericanos tienen cuestiones pendientes - tales como pretensiones territoriales, disputas sobre límites, regulación de los:recursos naturales compartidos, problemas de mediterraneidad, etcétera - para cuya adecuada solución conviene contar con una opinión internacional favorable. Temas tan candentes, como la posibilidad de que algunos países latinoamericanos ingresen en el "club" 
de los privilegiados que poseen armas nucleares, no pueden abordarse de manera autónoma e independiente, pues pueden alterar el "equilibrio de poder" (o "equilibrio del terror"). Y I ante esta situación no es dable pensar que las grandes potencias - que ponderan. aquel equilibrio- puedan permanecer impertéritas.

Las cuestiones de seguridad preocupan a los países latinoamericanos. Debe reconocerse, por un lado, que la "détente" -vale decir, la distensión en el conflicto Este-Oeste- permitió un mayor margen de maniobra a todos los países del mundo, en la medida que no resultaba necesaria una férrea alineación detrás de las posiciones de las grandes potencias en pugna. El surgimiento de los llamados "países no alineados" así parece indicarlo. Sin embargo, las tendencias más recientes en la arena internacional parecen reavivar ciertas actitudes que reafirman la vigencia de ciertas posiciones incompatibles entre el mundo occidental y el mundo comunista. En Estados Unidos.existe una marcada preocupación por dejar sentado que favorecer la "détente" no debe interpretarse como ceder posiciones que hacen a la defensa del funcionamiento de su propio sistema político y económico. Durante la campaña electoral, tan grave fue la preocupación que algunas veces se prefirió ni mencionar siquiera la "détente", por temor a que se la interpretara como sinónimo,de debilidad o de posición perdeclora. $Y$ es sabido que en Estados Unidos ser "perdedor" es poco menos que anatema.

Por otra parte, a los "países no alineados" cada vez les resulta más difícil mantener, en cuanto bloque, su "no alineación". İn la última reunión de estos países, realizada en. Colombo, Sri Lanka, en agosto de 1976, esta característica resultó patente, vista la dificultad de encontrar posiciones comunes ante los temas eminentemente políticos. Sil se pudo lograr cierto consenso en cuanto a los temas económicos (los reclamos por una mayor justicia en. las reláciones económicas internacionales: oportunidades de comercio, recursos financieros para el desarrollo, regulación de las empresas multinacionales y de la transferencia de la tecnología, precios de los productos básicos, etc.). Con lo cual la "no alineación" parecería identificarse, en última instancia, con las posturas económicas de los países en desarrollo, cuyo portavoz más destacado ha sido, hasta ahora, el "grupo de los 77 " en la UNCTAD". En definitiva desde un punto de vista estrictamente político y de la seguridad, sigue estando vigente una cierta alineación, aun cuando la misma - por razones tácticas- no sea hecha ostensible por los distintos paises. 
¿Qué será de América Latina con Carter? La respuesta a esta pregunta, el tema de este ensayo, necesitaba la introducción precedente. En efecto, no puede pensarse que la futura política latinoamericana de Estados Unidos dependa exclusivamente de la idiosincrasia de James Carter. Cualquiera que fuere la personalidad del nuevo mandatario norteamericano -su vigor, su vocación de cambio, su afirmación y defensa de ciertos valores-, las decisiones sustantivas más importantes no pueden desglosarse del contexto que las rodea. En ese contexto se destaca la situación económica y política mundial $y^{\prime}$ la particular relevancia o irrelevancia que allí pueden tener las cuestiones latinoamericanas. Carter necesitará adecuarse a esa situación, para así poder conjugar los intereses de su propio país. Estos incidirán con igual fuerza. El presidente norteamericano "se debe" al electorado que lo proclamó en las urnas, así que deberá atender sus necesidades. En primer lugar, entonces, la política exterior norteamericana resultará de una doble adecuación: a la circunstancia política-económica (o mundial) y a la circunstancia político-económica interna (o nacional).

En segundo lugar, debe tenerse en cuenta que la política exterior norteamericana no es obra exclusiva del Poder Ejecutivo. La responsabilidad por la conducción de dicha política es compartida con el Congreso. En el curso de la historia de Estados Unidos esa competencia compartida ha tenido, de hecho, diversas alternativas en función de la mayor o menor armonía entre ambos poderes. Ese grado de armonía ha clependido, en parte, de la circunstancia de que en el Congreso la mayoría perteneciera al mismo partido político que el Presidente. Ello no fue así clurante el gobierno republicano, derrotado ahora por Carter. No debe extrañar entonces que, en ese período, las relaciones entre ambos poderes no fueran fluidas en lo referente a política exterior. Carter se propone ahora mantener una relación muy armónica con el Congreso para la formulación de la política exterior. Esto se traducirá dándole una mayor ingerencia y participación en la adopción de las decisiones pertinentes.

¿Qué puede significar esta mayor ingerencia del Congreso en la formulación de la política exterior de Estados Unidos? Pues que la necesidad de atender la circunstancia político-económica interna (o nacional) se verá doblemente reforzada. En una democracia como la de Estados Unidos los representantes y senadores tienen generalmen- 
te una estrecha relación con su electorado. Tiste suele explicitar claramente cuáles son sus pretensiones y aspiraciones y, en la medida que "su" senador o "su" representante las tenga efectivamente en cuenta, le mantendrá su apoyo.

En tercer lugar, hay que tener en consideración las tendencias históricas de la política exterior norteamericana. En líneas generales, Estados Unidos ha oscilado entre el "aislacionismo" y el "intervencionismo".

Ha habido épocas en la historia en que Estados Unidos ha preferido replegarse sobre sí mismo. Ello ha sido facilitado por el gran potencial económico y militar norteamericano. Estados Unidos, basado en una autosuficiencia casi absoluta, aunque sin prescindir totalmente del resto del mundo, ha centrado su foco de atención y sus intereses dentro de sus propias fronteras, limitando sus relaciones externas a los contactos y necesidades imprescindibles. En otras épocas de la historia, Estados Unidos ha preferido asumir un papel activo en relación al resto del mundo. Esto ha sucedido en aquellas cir. cunstancias en las cuales consideraba que el mantenimiento de su nivel estaba en parte supeditado a su capacidad para controlar estrictamente los lineamientos del orden mundial. Para tal fin Estados Unidos ha considerado necesario intervenir activamente en el devenir político y económico del resto del mundo, estableciendo alianzas muy comprometidas con aquellos países o grupos de países a los cuales consideraba - por xazones de estrategia económica, política o militar- como cruciales o vitales para el mantenimiento de su propio poderío. Con esa óptica cada país o cada región era evaluado en función de aquellos criterios $y$, consiguientemente, cuanto más alto estuvieran en la escala de la importancia estratégica mayor era la preocupación de Estados Unidos por tenerlos a su lado.

En la actualidad, Estados Unidos ha adoptado una actitud intermedia que no tiene visos de cambiar.

Por un lado, Estados Unidos está consciente de que en el mundo interdependiente en que vivimos ya no es posible adoptar, posiciones aislacionistas. Las interacciones de los distintos países que componen el universo se han incrementado con el correr del tiempo.debido a razones por todos conocidas. La complejidad de la economía mo. derna, los progresos cientílicos y tecnológicos, los problemas comunes del medio ambiente, la utilización de espacios y recursos naturales compartidos por toda la humanidad, como los océanos y el espacio aéreo, hacen que prácticamente sea imposible que un pais pueda permanecer aislado de los demás, si es que no quiere quedarse a la zaga en la carrera del progreso. Además, la revolución en las comunicaciones no solamente facilita las interacciones entre los 
cliversos países sino que también actúa como acicate para aumentar el conocimiento de lo que sucede más allá de las fronteras nacionales. Estos conocimientos -económicos, políticos, culturales, etc.-, Iuego se transforman en deseos o necesidades que hay que satisfacer, para lo cual se debe interactuar. La revolución de las expectativas crecientes, en el nivel.internacional, se explica en parte debido a este fenómeno. $Y$ esa revolución es un factor más que coadyuva en el sentido de impedir cualquier intento aislacionista.

Por otro lado el perfeccionamiento de las armas de larga distancia ha quitado valor estratégico a ciertos países que antes eran considerados claves. Éste, y otros cambios en la tecnología bélica, tornan innecesaria la costosa presencia. (o control) de Estados Unidos en muchas partes del mundo. El gobierno norteamericano ya no puede justificar ante los contribuyentes (tax payers) cuantiosas erogaciones para el presupuesto de defensa. El intervencionismo ha.debido ceder parcialmente ante las nuevas realidades.

Decíamos más arriba que no puede pensarse que la futura política Jatinoamericana.de Estados Unidos vaya a depender exclusivamente de la idiosincrasia de James Carter, pero ésta también influirá en dicha política. ¿Cuál es la idiosincrasia de James Carter? No es posible todavía delinear acabadamente la personalidad.del presidente recientemente elegido en las elecciones norteamericanas. De acuerdo con lo que ha mostrado y demostrado durante la campaña electoral y el período de transición, Carter aparece como un representante típico del americano medio: por un lado con sólidos principios morales y religiosos que se esmera por destacar y enfatizar; por otro lado Carter aparece como un hombre pragmático que aprecia los logros concretos, que prefiere los resultados positivos sólidos más que los espectaculares. También valora el esfuerzo individual y la fuerza de voluntad: es un arquetipo del self-made-man. (En realidad, teniendo en cuenta su rutilante ascenso político, basado fundamentalmente en lo que él mismo fue creando, Carter bien puede ser considerado un self-made-president). En una reciente entrevista publicada por la revista Time, a Carter le fue.formulada la siguiente pregunta: "Algunos han expresado su preocupación acerca de su filosofía política, en la cual verían una tendencia hacia el "igualitarismo". ¿¿Cuál es su opinión sobre la cuestión de la igualdad versus la iniciativa individual?". La respuesta fue la siguiente: "No me inclino por una sociedad homogénea en la cual aquel que es fuerte o hábil o brillante o, incluso, afortunado, sea castigado, y su sustancia - me refiero, ahora, a su sustancia financiera- le es quitada y distribuida entre aquellos que están menos motivados". Esta filosofía .individualista, trasladlada al plano internacional, pue- 
de tener serias consecuencias para la política que se adopte en relación a los paises en desarrollo. Puede significar, por ejemplo, que Carter preferirá ayudar a aquellos países que, a su vez, confiados en sus propia fuerzas, se esmeren por ayudarse a sí mismos (selfreliance).

O sea: Carter es, en parte, "principista" y, en parte, también es "realista pragmático". Esta dualidad estará presente necesariamente en los momentos en que el presidente electo adopte decisiones políticas. Todo dependerá de la circunstancia que rodee.cada toma de decisión para saber cuál característica predominará.

Podemos adelantar, desde ya, que suponemos que las circunstancias económico-políticas mundiales, a.que nos hemos referido más arriba, obligarán al presidente Carter a inclinarse por su vertiente pragmático-realista. En efecto, cabe reiterar que la situación por la que atraviesa el mundo contemporáneo obliga a.actuar con criterios flexibles y no rígidos, que permitan la obtención de resultados satisfactorios para todas las partes involucradas. Ya nadie puede asumir riesgos que conduzcan al mundo a callejones sin salida. El peligro de que un conflicto limitado se expanda y desemboque en una conflagración. nuclear está siempre presente.

\section{LOS PROBLEMAS PRINCIPALES}

¿Cuáles serán los principales problemas que abordará Carter y cómo afectarán a América Latina las soluciones que se den a sí mismos? El principal problema que debe abordar Estados Unidos es económico. En efecto, los grandes trastornos que viene sufriendo la economía mundial, trastornos que se agudizaron desde 1973 con los incrementos del precio del petróleo, todavía no han podido ser solucionados satisfactoriamente. Inflación, recesión, desocupación son características que ya no pertenecen solamente al mundo en desarrollo, pues han pasado a definir también a las economías desarrolladas. Durante estos últimos años Estados Unidos ha estado tratando de superar los escollos económicos. A partir de 1976, especialmente en la segunda mitad del año, los indicadores económicos han ido mejorando progresivamente. Pero dicha mejoría no ha sido tan grande como la mayoría de los vaticinios insinuaban al promediar 1976. La tasa de desocupación en Estados Unidos continúa oscilando alrededor del 8 por ciento. Éste es un dato que habla por sí solo y que ciertos países latinoamericanos no parecen considerar debidamente, 
pues teniendo algunos de ellos una menor tasa de desocupación, igualmente presentan sus reclamos económicos en forma airada.

Parece claro que Estados Unidos deberá tratar de resolver urgentemente sus problemas económicos. Dado que sus recursos no alcanzan para todo y para todos, es lógico suponer que establecerá ciertas prioridades con ese.criterio universal que dice que "la caridad bien entendida empieza por casa". Si recordamos lo que dije más arriba en el sentido que el presidente Carter se "debe" a su electorado, $y$ que el Congreso se lo recordará constantemente, podemos suponer que Estados Unidos no dispondrá de suficientes recursos como para atender los reclamos y expectativas provenientes del resto del mundo y en especial de América. Latina. He aquí el "quid" de la cuestión.

En la medida que se comprenda esto último será posible comprender la futura política exterior norteamericana y sus implicancias para América Latina. Las distintas facetas de esa politica exterior norteamericana estarán teñidas por esas circunstancias. Durante el gobierno de Carter es muy probable que empiecen a concretarse ciertas políticas referentes a temas ya mencionados más arriba, que interesan. especialmente a América Latina como: 1) La producción, elaboración (transformación), comercialización y precios internacionales de las materias primas; 2). Las inversiones públicas y privadas de Estados Unidos en el exterior y la actividad de sus empresas multinacionales; 3) La transferencia tecnológica desde Estados Unidos hacia los paises en desarrollo y, en especial, hacia los países latinoamericanos; 4) La liberalización del comercio exterior (a América Latina le interesa acceder con sus productos en el mercado norteamericano) .

La consideración de los cuatro temas premencionados puede hacerse de dos ópticas diferentes. Una sería analizar los distintos pormenores técnicos con los cuales se puede llegar e implementar las políticas acerca de esos temas. Al respecto serían muchos los análisis pertinentes según las distintas alternativas que pueden elegirse, y las modalidades que se prefieran. No voy a entrar en ellas porque excedería el marco de este ensayo. Lo que sí me interesa destacar es otra óptica, que hace al enfoque global de los problemas. Si tenemos en cuenta que Estados Unidos debe administrar cuidadosamente sus recursos a fin de satisfacer los reclamos económicos internos, es dable pronosticar lo siguiente. Durante el gobierno de Carter se intensificarán aquellos programas económico-políticos externos que faciliten, a su vez, la recuperación económica interna de Estados Unidos. Dicho en otras palabras, no puede esperarse una política de cooperación externa norteamericana de tipo "concesional" o "gratuito". Estados Unidos buscará afianzar aquellas líneas de cooperación en 
donde, a la vez que se satisfacen los intereses de terceros países, también queden satisfechos los intereses nacionales.

Aquí puede entrar en escena América Latina. Y lo puede hacer en forma preponderante. Estados Unidos necesita concretar una política coherente con los países en desarrollo. Pero parece muy difícil poder abordar una política única, global, que abarque a todos esos países. Ellos son muy diferentes en su grado de desarrollo (al tercer mundo ya se le desgaja un cuarto y hasta un quinto mundo), en sus estructuras productivas y canales de comercialización, en sus sistemas políticos y afinidades ideológicas, en sus características étnicas y culturales, en su estilo de vida, etc. Resulta más viable que Estados Unidos intente primero, y en forma más concreta y detallada, tratar con un sub-grupo de los países en desarrollo.

En este sentido América. Latina aparece ante Estados Unidos como la región más apropiada del mundo en desarrollo para intentar una nueva política. Hay muchas razones para que así lo haga. En efecto, a Estados Unidos le interesa América Latina porque: a) Una porción considerable y sensible de sus inversiones, de su comercio y de sus empresas multinacionales tienen que ver con la región latinoamericana; b) Por una larga tradición de relaciones mutuas; c) Por su proximidad geográfica.

El Partido Demócrata parece haber tenido en cuenta estas consideraciones ya que en su plataforma electoral establecía que "los principios de la política del buen vecino" y de la Alianza por el Progreso, por los cuales nos comprometemos a trabajar con todas las naciones de las Américas en un plano de igualdad aunque siguen siendo válidos, hoy parecen haber sido olvidados por el gobierno actual".

Las modalidades que pueda adoptar una nueva política norteamericana respecto de América Latina dependerán de ciertos factores que podemos destacar.

En primer lugar está la cuestión acerca de si Estados Unidos privilegiará a América Latina con un trato preferencial distinto al que otorgue a otras regiones en desarrollo. Aquí habrá que distinguir lo que se haga en la práctica de lo que se proclame formalmente. En la práctica es probable que América Latina reciba una consideración preferente por parte de Estados Unidos. Formalmente, y a fin de no malquistarse con otras naciones en desarrollo, es probable que Estados Unidos no instrumente ostensiblemente, de manera demasiado destacada, sus futuras relaciones con América Latina. $O$, en todo caso, Estados Unidos podría formalizar un programa con América Latina a la par que instrumentaría una política global para con todo el mundo en desarrollo. 
En segundo lugar, un nuevo programa de cooperación con América Latina no necesariamente se concretará, desde su iniciación, con igual énfasis para todos los temas y con todos los países de la región. De la misma manera y por las mismas razones pragmáticas que Estados Unidos preferirá concretar con una de las regiones en desarrollo (América Latina) su política al respecto, es probable también que Estados Unidos prefiera (en la práctica, no formalmente) comenzar seleccionando algunos temas y países con los cuales estime tener mayores probabilidades de éxito. De esta manera se implementarán programas pilotos cuyo eventual éxito serviría de ejemplo (y produciría un efecto de demostración) que facilitaría su extensión a otros temas, países y regiones.

Finalmente '(last but not least), están las cuestiones políticas. El gobierno de Carter, respondiendo a las influencias del ala liberal (en el sentido norteamericano de este término) del Partido Demócrata tendrá sumo cuidado en sus relaciones con aquellos países latinoamericanos carentes de una forma democrática de gobierno, o acusados de violaciones sistemáticas de los derechos humanos de sus habitantes. En este último caso se podría llegar al cese de ayuda (militar e, incluso, económica). La opinión pública norteamericana está muy sensibilizada respecto de este tema y reclama una reacción oficial concordante. No sería extraño, entonces, que se impusieran sanciones económicas ejemplarizadoras contra algún país latinoamericano, que cumpliría así el papel de "chivo emisario". Sin embargo, no es dable pensar que Estados Unidos pueda Ilevar una discriminación de este tipo hasta sus últimas consecuencias. Primero, porque es probable que aquellos países latinoamericanos acusados de violar los derechos humanos modifiquen considerablemente sus prácticas y su imagen al respecto, a fin de no continuar sentados en el banquillo de los acusados. Segundo, porque si Estados Unidos acentuara el criterio de la compatibilidad política como condición para aplicar sus programas económicos externos, a fuerza de ser principista debería adoptar una línea "dura" similar con países amparados por la "détente" (URSS y bloque comunista), y con aquellos otros que, por razones estratégicas, procuran mantener buenas relaciones.

Este asunto de las compatibilidades políticas de Estados Unidos como condición para mantener una fluida vinculación económica requerirá una adecuada solución. En efecto la mayoría de los países latinoamericanos no tiene regímenes democráticos de gobierno; en cambio, algunos de los que sí tienen tal régimen han adoptado ciertas posiciones referentes al ordenamiento económico-político internacional en discordancia con la posición norteamericana. Es el caso 
de Venezuela, y su afiliación a la OPEP, que está sancionada por la Trade Act norteamericana de 1974. Venezuela también es uno de los adalides de los planteamientos tercermundistas, en lo cual ha estado acompañado por el México de Echeverría (todo parece indicar que López Portillo se apartará, a este respecto, de la línea de su antecesor). ¿Qué predominará en definitiva? ¿La afinidad política o la afinidad de los intereses económicos? Pueden esperarse soluciones pragmáticas, transaccionales, al respecto. Pues Estados Unidos no querrá afectar la posibilidad de continuar desarrollando sus inversiones en el Cono Sur, por ejemplo, cuyas legislaciones sobre inversiones extranjeras suelen ser más afines a sus pretensiones, aunque no lo sean sus sistemas políticos. La afinidad política con países como Venezuela probablemente influya para buscar soluciones transaccionales en el área de la economía internacional.

Hay otras dos cuestiones que Estados Unidos abordará con premura en América Latina. Una es el Canal de Panamá; la otra es Cuba. La primera es una cuestión mixta: existen factores económicos, , por un lado, y políticos y de seguridad, por el otro. El asunto de Cuba es fundamentalmente político y de seguridad.

El Canal de Panamá ya no tiene tanta importancia económica y estratégica para Estados Unidos como años atrás. Por otra ${ }_{\text {p }}$ parte, es una espina irritante para los panameños $-y$, en general, para el resto de los latinoamericanos- en virtud de sus connotaciones colonialistas y de sus reminiscencias de la política del "garrote". En 1974 los gobiernos norteamericano y panameño acordaron una declaración de principios, según los cuales Estaclos Unidos podría seguir operando en el canal - para lo cual continuará haciendo uso de la infraestructura y superficie de tierra necesarias- y Panamá tendría una mayor participación en los beneficios, administración y defensa del Canal. Panamá también recuperaría la jurisdicción sobre su territorio. Ello facilitaría la firma de un. nuevo tratado con el gobierno de Carter. Sin embargo, la cuestión sigue siendo ardua. Parte de la opinión pública norteamericana, con importantes voceros en el Congreso, ve en el Canal de Panamá una cuestión de honor y de prestigio nacional. No quieren sentirse "corridos" por las presiones locales. En definitiva, este tema, si bién apremiante, no parece haber evolucionado lo suficiente para darle una solución transaccional definitiva. Carter sabe esto y su estrategia al respecto es cautelosa en atención a ambas partes.

La posición norteamericana con respecto a Cuba dependerá de la continuación, o no, de sus incursiones en el resto del mundo. Cuando se habían logrado sustanciales progresos en pro de una reanudación de las relaciones con Cuba, la intervención de este país en An- 
gola hizo detener dicho curso. Vista la desconfianza en que ha caído la "détente", el gobierno de Carter no arriesgará comprometerse con Cuba hasta no tener asegurada la no ingerencia del pais del Caribe en los países africanos $y$, con mayor razón, en los latinoamericanos. El equilibrio de poder en el concierto de las naciones será un criterio que Carter mantendrá en cuenta.

¿INTERDEPENDENGIA DE FINES CON INTERDEPENDENCIA DE MEDIOS?

Las futuras relaciones de Estados Unidos con América Latina no deben analizarse con un criterio estático, vale decir, dando por sentado que la futura política latinoamericana vis-à-vis Estados Unidos permanecerá sin cambios. En los últimos tiempos América Latina ha estado mayormente inclinada hacia las reivindicaciones sobre las cuales ha venido insistiendo con fuerza el Tercer Mundo. Sin embargo, como se ha señalado (véase Marcelo E. Aftalión, "Un Dilema Latinoamericano", "Criterio", 10 de junio de 1976; "Comercio Exterior", mayo de 1976): "El mundo, en cierta medida interdependiente y necesitado de acuerdos consensuales, parece ir oricntándose a negociaciones muy concretas, en donde cada parte encuentra su contraparte, sea por necesidad, por interés, por afinidad o por cualquier otra razón".

¿Cuál será la contraparte de América Latina? (La autarquía queda descartada, sin. discusión, vista la interdependencia económica mundial). Por distintas razones, explicadas en el artículo recién citado, no pueden serlo ni Europa, ni Japón, ni la URSS. Así las cosas, a América Latina, le queda Estados Unidos como única potencia económica disponible (como contrapartida económica principal) para negociar en las cuestiones fundamentales mencionadas más arriba (comercio, inversiones, productos básicos, tecnologfa, etcétera).

No sería descartable, entonces, que América Latina buscara relacionarse de una manera más provechosa con Estados Unidos. Claro está que deberá ser. mutuamente provechosa. Además, América Latina querrá que esa nueva manera de relacionarse con Estados Unidos no le reste autonomía para elegir sus fines últimos, sus valores, y su estilo político. Se ha resumido esa nueva modalidad que podría adoptar la relación Estados Unidos-América Latina en la fórmula "independencia de fines con interdependencia de medios".

Por todo ello, es probable que, América Latina tienda a acercarse 
a Estados Unidos, dejando de lado la confrontación, y procurando negociar soluciones intermedias en aquellas áreas que hasta ahora han sido motivo de conflictivas diferencias.

Si logra articularse una posición latinoamericana, coherente $y^{\prime}$ realista, no cabe duda que el gobierno de Carter estará dispuesto a considerarla con detenimiento. Hasta ahora los latinoamericanos hemos estado acostumbrados a quedarnos a la espera de los acontecimientos: se han elaborado planes acerca de la política norteamericana para con América Latina y, a posteriori, cuando ya estaba todo decidido, han surgido las voces latinoamericanas para expresar su opinión. América Latina ya tiene suficiente madurez para presentar, motu proprio, un esquema sobre el futuro de las relaciones interamericanas. En la medida que lo haga, y rápido, pueden esperarse novedades de importancia en la futura política exterior norteamericana respecto de América Latina. Es responsabilidad principal de América Latina hacerse valer, y con suficiente peso, en el orden económico-político internacional. Si América Latina, ella misma, no demuestra su valía, nadie lo hará en su nombre y representación. De la iniciativa y articulación de esfuerzos latinoamericanos dependerá que no se repitan opiniones como la del Memorándum Plank (marzo de 1971, Consejo de Relaciones Exteriores de Estados Unidos), que decía: "América Latina, en última instancia, no es de importancia estratégica, política, económica, ideológica o vital para Estados Unidos". 